\title{
Quantitative Research on the Impact of Inquiry Learning on English Teaching Effectiveness
}

\author{
Ying Lu \\ Chengdu Neusoft University, Chengdu, 611844, China.
}

\begin{abstract}
Inquiry learning methods continue to play an important and positive role in English teaching. Classroom teaching is the main channel for implementing quality education in schools. With the continuous deepening of education reform, the reform will inevitably fall into the classroom teaching. In order to carry out researches on meaningful receptive learning, the role of inquiry-based learning is gaining more and more attention. This paper analyzes and studies the function and practice of inquiry learning method in English teaching from the perspective of school education environment.
\end{abstract}

Keywords: Inquiry learning, English teaching, effect, influence, quantitative research.

\section{Introduction}

With the enrollment expansion of ordinary high schools and universities, the demand for students in our country is also getting higher and higher. Many vocational students are not interested in learning English and generally have a poor foundation. They often hold the attitude of giving up. In the traditional English teaching in secondary vocational schools, most of them neglect the interaction between teachers and students, ignore the students as the main body of teaching, and seriously curb the students' learning autonomy and enthusiasm. Interest is the best teacher, according to these circumstances, I make the following inquiry, students only interested in learning English to improve their level of learning.

As a teacher of student learning, the teacher's task is to mobilize the enthusiasm of the students and encourage them to acquire knowledge and develop their own capabilities so that they can find problems, ask questions, analyze problems and solve problems by themselves. Therefore, how to teach the students to be the masters of their own learning and to enhance their self-confidence, enthusiasm and creativity from the perspective of cultivating their interests is an important issue that every education practitioner must study and solve. Due to the difference of educational philosophy, teaching mode and educational environment, international schools have always played an important and active role in their teaching as especially in the aspect of English teaching, compared with other traditional teaching methods, Strong real meaning.

Inquiry leaning means that under the guidance of the teacher, the students discover the problems by themselves and use the research methods of observation, comparison, analysis, judgment and reasoning to solve the problems and acquire new knowledge and improve their practical abilities learning activities. This kind of learning can effectively improve students' interest in learning, improve students' thinking ability and improve students' ability to solve problems. To grasp the characteristics of inquiry learning is an important premise and basis for our inquiry teaching.

\section{The Proposed Methodology}

The basic concept of inquiry learning. Inquiry learning is a positive learning process, mainly refers to students learning to explore their own problems in learning. Specifically, inquiry learning refers to setting up a kind of situation or approach similar to scientific research by using questions as a carrier in the process of teaching, guiding students to collect, analyze, process information by themselves, and feel and experience the production process of knowledge, so as to understand Society, learn to learn, develop analytical ability to solve problems, problem-solving skills and creativity, the core is to change the way students learn. In-class inquiry learning is to explore the main learning. Specifically, it refers to the teaching process is under the guidance of the teacher's inspiration, under the premise of independent study and cooperative discussion of students, the current textbook as the basic inquiry 
content, with the world around students and the actual life as the reference object, to provide students with full freedom of the expression, question, explore, and discuss the opportunities for students to try their own activities through various solutions such as individuals, groups, and groups, and apply what they have learned to solve practical problems. In-class inquiry learning pays special attention to developing student's intelligence, developing students' creative thinking, developing self-learning ability, and trying to guide students to learn and master scientific methods through self-exploration, so as to lay the foundation for lifelong learning and work.

The Role of Inquiry Learning in English Teaching. Improve student self-learning ability in student quality training. Suhomlinski said: "There is a particularly strong need in the child's mind, which is to feel like a discoverer, researcher, and explorer." This need arouses the desire of students to explore. We know that student learning is not simply a cognitive process, but a cognitive and emotional collaborative process, both of which are indispensable. Therefore, in the English classroom teaching, we must create an engaging problem situation inspire students to explore the desire to give the thinking a strong internal drive. For example, when I was teaching the third theme "rainforest", I would first put a video about the rainforest and then set up a "Question Time" panel in the classroom to discuss with them two groups about "rainforest" Question, and then to the group as a unit, select the two relatively important issues written on the display board affixed above. Motivation is immediately mobilized when students learn that their own problems will be exhibited during the entire exhibition. After writing the questions in each group, I led the students to the computer lab to show the students first if they used the Google search engine to search for information. The students then went online to find out the answers to the questions they had raised earlier and to copy the answers behind the newspaper affixes. Such "Question Time" panels actually become the knowledge panels that open the questions and see the answers. Throughout the process of inquiry, students have shown a keen interest in the theme of the rainforest. While actively thinking about it, they exercise their ability to use the Internet to search for information. Teachers can easily teach and students learn happily. Therefore, teachers should be good at exploring teaching resources, guide students to conduct independent inquiry learning anytime, anywhere to enable students to gradually learn to learn.

In the teaching plan preparation, clear the mission of teaching objectives. If you do not have a clear and specific goal to guide you, you will feel at a loss as you explore and evaluate. With the goal of exploration, students will not lose their way while studying, and fragmented and divergent thinking can be concentrated. To design and develop the research objectives and tasks of each lesson, teachers and students must define the theme of inquiry. A certain task is to explore the starting point and destination of learning. The inquiry tasks proposed in class should be suitable for students 'thinking level and cognitive ability, and have certain challenges. They can stimulate students' motivation to learn, arouse students 'interest in inquiry, and sufficiently arouse students' inquiry activities. For example, when I was teaching how to write an English instruction, I asked the students to create a game in pairs and write the game in a clear way. Then I demonstrated it in front of the students according to my game description as own game instructions to make the necessary changes. For thirdgraders, when it was said that "game" enthusiasm was immediately mobilized, discussions, drafting, demonstrating and amending a series of inquiry activities were held under this interesting task. In the inquiry, the teacher must have some people in mind, pay attention to the study of students, understand the needs of students, understand the learning situation, and guide them to choose their own needs learning objectives.

Application of Inquiry Learning in Teaching Practice. Objectively provide students with the space and conditions for independent inquiry learning guarantee. In the classroom, teachers should believe in the potential of students, abandon cumbersome analysis and quest for hardcore beatings, focus on strengthening students' self-study and exploration, give time, give opportunities, give guidance, teachers try hard to guide and teach students to think independently and learn cooperate with others, give the right to ask students, return the time to the students, and give the students the opportunity to boldly let go, to ensure that students have enough time and space to read, self-awareness and selfexpression. 
Subjectively protect students' enthusiasm for learning and strengthen process guidance. In inquirybased learning in the International School English classroom, students have to spend most of the time at their discretion because students acquire knowledge and apply knowledge on their own, requiring a process of inquiry, a process of understanding, a process of thinking, a process of self-digestion Process, a process of personal experience. With a certain amount of time, students have to explore and understand the possibility of acquiring and applying knowledge. Moreover, students in the process of inquiry, the need for a certain amount of space for activity, that is, need to facilitate students to explore and use knowledge of venues. A single classroom space, fixed seats, monotonous blackboard is not conducive to students to explore their own knowledge and use of knowledge. But if it is the instant inquiry learning in class, "group cooperative learning" is a better form of learning, which is a bridge for students to explore successfully. At present, some people think that the traditional way of teaching is infused, while the teaching of inquiry-based learning is to give students "complete" freedom, and what students like to do even if the inquiry has nothing to do with the subject. This is essentially a misinterpretation of inquiry learning, is a kind of laissez-faire teaching. Modern teaching theory tells us that the traditional one-way passive teaching should be developed into a multidirectional initiative innovation teaching mode. Affected by psychology, physiology and cognition, it is impossible for primary school students to learn independently. Therefore, teachers in teaching guidance, organization, help, cooperation is essential. In the course of inquiry learning, students learn mainly through peer cooperation or group cooperation. They need to analyze the problems or tasks of inquiry. They need to use a variety of methods to collect information, analyze information, formulate solutions and obtain results. They need to improve their works by expressing and exchanging, verifying or revising their own explanations. In the process, teachers mainly organize and instruct the students' inquiry activities, so that they can complete the inquiry tasks successfully and achieve the goal of inquiry study.

Improve preview ability. In the inquiry learning process, preview is the most basic stage, but also an important period for students to explore their own learning. Sukhomlinski once said that the independent study time is the free time of the students. Only when the students control the time independently can become the main body of study. This is just the necessary condition to ensure the individual development of the students. The time of autonomous learning is the necessary condition for inquiry learning. Teachers should ask some open questions before asking students to prepare, but they must give enough time for students to learn. Only when the students can make a solid foundation by preview can they explore and discover the problems proactively to improve the efficiency of classroom teaching.

Model law. Students are relatively poor at learning ability, so teachers should teach the students in advance of the preview and should design reasons for such preview. Demonstration is a demonstration that can be done in class so that students understand the importance of preparation and progressively develop the good habits of preparation.

Recitation method. Reading is an important method of English learning, which is the Basic English learning methods, English only read out to develop the habit of preview, read out to deepen the understanding of the content. In the process, teachers should pay attention to the teaching of reading aloud to students, and students are still lacking in the skills of reading aloud.

Comment method. Annotation is an important way to test their own learning, annotation can highlight the key points, teachers can highlight the contents of the student annotations, teachers should actively guide students in the learning process will be expressed where the doubt, and marked in the next blank, In order to facilitate discussion between students.

Mutual aid law. Teachers should actively encourage students to encourage each other and actively solve the problems in the course of previewing.

Design fresh topics. Good start is half done. Fresh topics are just the premise of classroom learning. Good introduction of the classroom can quickly grasp the students 'attention so that they can stimulate students' interest in learning. This is very important for secondary vocational students to learn English. Classroom should focus on the correctness of the import, the content needs to be integrated with the course content, the introduction of fresh topics can be out of the traditional obsolete learning content, 
such as through a movie, a poem, a story and a reading, etc., before joining the class According to the students 'actual learning situation, to stimulate students' interest in learning, not only can give students a fresh feeling, but also can improve the efficiency of classroom teaching and improve their interest in learning. Teachers should start from the actual situation of secondary vocational students, under normal circumstances, the more the learning content introduced before class closer to the textbook content, the more able to stimulate students' interest in learning, which will achieve a positive and guiding effect. This method of introduction not only enhances students 'curiosity, but also fosters students' ability to combine graphics and texts. Students are very curious about this.

Inquiry learning needs to interact through a certain learning situation, and students can enter the discussion consciously in this process. Teachers should actively consider students 'psychological structure and cognition to actively explore the students, so as to stimulate students' Internal driving force. For example, when studying English culture differences between English and Chinese, teachers should first ask students to understand Chinese traditional culture, learn about the characteristics of each animal in the 12 zodiac signs, and see if they have some of the characteristics of their own. The students are then divided into groups to discuss and ask whether the foreigner also has 12 Chinese zodiacs. The final conclusion is: the West has 12 constellations, their astrology is affected by the moment of birth, astrologers to analyze their character, and can predict what kind of event can be encountered in the future. During the course of class discussion, teachers can actively guide students to learn how to divide the constellation, and let students find their own astrology according to their birth time. After describing themselves, they can also learn to describe the people around them. In this classroom environment teaching will be smoother, students also naturally grasp the character of some characters, while understanding the Chinese and Western cultures, broaden their knowledge.

Modern classroom education should be full of vitality education. Therefore, in classroom teaching, we must change the concept of education, change the way of learning, reform the model of personnel training, teachers should not set too many rules and regulations, require students to pre-designed according to a set of teachers to run. Seriously study and experiment with heuristic and inquiry learning. Students are welcome to take the initiative to participate in teaching and let the students learn by themselves. The teaching process mainly depends on the students themselves.

\section{Conclusion}

Inquiry learning is a mature and young teaching method that has been practiced through years of inquiry learning activities. Conducting interactive education, the main body of students greatly enhances the awareness of practical ability and research ability has been improved. Inquiry learning does have a good promotional value, hoping to have more students benefit from this good teaching method in order to promote the process of quality education.

\section{References}

[1]. Klassen, R.M. and Tze, V.M., 2014. Teachers' self-efficacy, personality, and teaching effectiveness: A meta-analysis. Educational Research Review, 12, pp.59-76.

[2]. Marcellino, M., 2015. English language teaching in Indonesia: A continuous challenge in education and cultural diversity. TEFLIN Journal, 19(1), pp.57-69.

[3]. Kini, T. and Podolsky, A., 2016. Does teaching experience increase teacher effectiveness. A Review of the Research.

[4]. Xiaoqin, H. and Zujian, C., 2015. The Effectiveness of the Furniture Design Teaching Research. Furniture \& Interior Design, 12, p.039. 